\title{
AN INVESTIGATION INTO THE PURITY OF AMERICAN STRAINS OF BACILLUS BOTULINUS
}

\author{
GEORGE F. REDDISH
}

From the Sheffeld Laboratory of Bacteriology, Vale University, New Haven, Conn.

The descriptions of Bacillus botulinus by the various investigators of this country differ markedly in certain respects from those of van Ermengem ${ }^{1}$ and other European investigators. What is 'particularly noteworthy is that odors of putrefactive decomposition were not noted by the latter.

In a recent study of $\mathrm{B}$. botulinus the author employed 19 different strains of the organism. These were obtained from various laboratories and came originally from many sections of the United States. A preliminary examination of some of these strains soon gave some indications of impurities in the cultures. Consequently, all of the 19 strains were subjected to anaerobic plate cultivation. In every instance but one toxic and nontoxic cultures were obtained from the stock strains. In the one exceptional case only a single attempt was made. Nontoxic cultures were obtained from some of the stock strains only after repeated efforts. These had all the characteristics of $B$. sporogenes.

The method of isolation of $B$. botulinus quite generally employed by American investigators may be of particular significance here. Inoculations were made into deep glucose-agar tubes, and after certain periods of incubation transfers were made from colonies in the depths of the agar. It is true that on some occasions preliminary enrichment and dilution were resorted to, but in few, if any, instances were the transfers made from exposed surface colonies. Graham and Brueckner ${ }^{2}$ made their transfers from deep colonies developing in glucose gelatin plates.

McIntosh and Fildes " criticize the deep agar method of isolation of anaerobes as tending to yield impure cultures. They further state: "It cannot here be impressed too strongly on the worker that the purity

Received for publication, March 20, 1921.

1 Centralbl. f. Bakteriol,, O., 1896, 19, p. 442; Ztschr. f. Hyg. u. Infektionskr., 1897. 26, p. 1

2 J. Bacteriol., 1919, 4, p. 1.

3 Med. Research Com., Special Report Series 12, 1917. 
of anaerobes can only be tested and controlled by repeated surface cultivation." Van Ermengem and other European investigators succeeded in their isolation of $B$. botulinus by the use of the anaerobic plating method.

The author's method of preparing anaerobic plates, which differs little from that of Stoddard, ${ }^{4}$ is as follows:

From the supernatant liquid of a 2 to 4 day culture of $B$. botulinus in egg-meat medium 0.2 to $0.3 \mathrm{cc}$ is added to $10 \mathrm{cc}$ of sterile salt solution in a test tube containing well-washed sand. The tube is closed with a previously sterilized rubber stopper and shaken vigorously for 3 or 4 minutes; $0.5 \mathrm{cc}$ of this suspension is added to a second $10 \mathrm{cc}$ of salt solution and sand and shaken as before. This process is again repeated. With a bent glass rod the final suspension is streaked over the surface of glucose-agar plates which have been dried at $37 \mathrm{C}$. over night to eliminate excessive moisture from the agar surface. These plates are incubated for 3 days at $34 \mathrm{C}$. in a closed jar from which the oxygen has been removed by the hydrogen replacement and vacuum pump exhaustion method.

By this method an organism in every way resembling $B$. sporogenes was isolated from all but one of the stock cultures. Isolations of B. sporogenes were made from original "strains" of $B$. botulinus by four different methods, namely, by the procedure described in the foregoing, by simple dilution, by aerobic plating with Staphylococcus aureus (Sturges), and by the heating of young cultures which contained only the spores of $B$. sporogenes and vegetative forms of $B$. botulinus.

The isolations of the nontoxic strain (B. sporogenes) were made from colonies closely resembling those of $B$. sporogenes. The nontoxicity was determined by the injection of $1 \mathrm{c} c$ of a $1: 10$ dilution of the supernatant fluid of egg-meat cultures into the peritoneal cavity of the white mouse. All the cultures which proved non-toxic were further incubated for 3 weeks at room temperature, and again tested for toxicity. Furthermore, tests were also carried out on guinea-pigs. After 4 days' feeding of the guinea-pigs with these strains grown for 4 weeks in egg-meat medium no symptoms of poisoning were observed. On the other hand, a small amount of material from toxic cultures obtainerl from the same plates and prepared in the same way killed the guineapig in less than 24 hours.

Toxic cultures were obtained from colonies which were more or less smooth and regular; and again from others which were less smooth or which even resembled typical colonies of B. sporogenes. All of

- Jour. Am. Med. Assn., 1918, 70, p. 906. 
these toxic cultures decomposed the egg-meat medium with the evolution of foul odor, but less extensively and less rapidly than did the nontoxic cultures. Their toxicity was determined in the same way as those which proved by animal experimentation to be innocuous. It appears from the evidence at hand that none of these toxic stock "strains" should be considered as pure cultures. It is quite apparent, however, that they contain the $\mathrm{B}$. botulinus, whereas the nontoxic strains were freed from this organism, and in every way resembled pure cultures of $B$. sporogenes.

A comparative study was made of the toxic and nontoxic "strains" in their relation to gas production from glucose, lactose, levulose, galactose, maltose, and sucrose, with these results: The nontoxic strains readily attacked glucose, levulose and maltose, whereas the toxic "strains," while exerting the same action on the glucose, levtlose and

TABLE 1

Showing Representative Gas Production in the Sugar Broths yy the Toxic and Nontoxtc Cultures

\begin{tabular}{c|c|c|c|c|c|c}
\hline Cultures & $\begin{array}{c}\text { Dextrose } \\
\text { Percentage }\end{array}$ & Lactose & Suerose & $\begin{array}{c}\text { Maltose } \\
\text { Percentage }\end{array}$ & $\begin{array}{c}\text { Levulose } \\
\text { Percentage }\end{array}$ & Galactose \\
\hline Nontoxic....... & 80 & 0 & 0 & 40 & 15 & $\begin{array}{c}\text { Occasional } \\
\text { bubble } \\
\text { oceasional } \\
\text { bubble }\end{array}$ \\
Toxic.......... & 80 & + & + & 40 & 15 & 15 \\
\hline
\end{tabular}

maltose as did the nontoxic, also produced a small amount of gas from lactose and sucrose. An occasional bubble of gas was produced in galactose broth by both. Table 1 serves to illustrate the differences in gas-producing power in the different sugar mediums.

Inability to attack lactose and sucrose is characteristic of B. sporogenes. The action on glucose, maltose and levulose is also typical of this anaerobe. Furthermore, the morphology and various cultural characteristics, particularly the rapid decomposition of egg-meat, with the production of offensive odors, are added evidence that the nontoxic strains isolated from the original toxic stock cultures are B. sporogenes. The occasional formation of gas in the galactose broth tubes may be attributed to slight impurity in the galactose, though all of the carbohydrates employed were of the highest purity obtainable. The basic beef-extract broth was shown to be free from dextrose by inoculation with $\mathrm{B}$. coli and a stock strain of $\mathrm{B}$. sporogenes. The test mediums were made from plain beef-extract broth $\left(\mathrm{P}_{\mathrm{H}} 7.2\right.$ to 8.0$)$, to which $1 \%$ of 
the carbohydrate was added. The medium was filled into large doublebarreled Durham fermentation tubes in liberal amount, and covered with a layer of high grade neutral mineral oil.

In table 2 are given the sugar reactions and toxicity tests of two representative nontoxic strains isolated from each so-called "strain" cf $B$. botulinus tested; also the reactions of the toxic isolations from the strain from which nontoxic cultures were not obtained. The organisms included in the first part of the table were isolated from sporogeneslike colonies and were similar in their action on meat mediums and milk to pure cultures of $B$. sporogenes; the others were obtained by 3 other methods. They are all gram-positive anaerobes, with subterminal spores. Toxicity tests were made on white mice, a 1: 10 dilution of the supernatant liquid of a 7 to 10 day old egg-meat culture at $37 \mathrm{C}$. being injected intraperitoneally. If symptoms of botulism and death did not occur within 48 hours, the inoculation test was considered as negative and the culture nontoxic. The sub-strains from strain 8 of this series, although showing B. sporogenes-like colonies, were all toxic. This strain was plated only once. The toxicity of the organisms fished from B. sporogenes-like colonies may be explained on the assumption that B. botulinus spores were within the colony, but that they had not germinated, or that little multiplication had taken place. It is quite probable that if further attempts had been made to isolate nontoxic substrains from this stock strain, such would have been obtained. The plating technic was checked in every possible way to make sure that no contamination had been introduced. The original "strains" were tested occasionally to determine their constancy. Nontoxic strains were isolated from one culture by the simple dilution method which Sturges and Rettger ${ }^{5}$ used with such success in isolating B. putrificus. A microscopic count was made of the rods and spores in a salt stuspension of one of the stock strains of B. botulinus, and this diluted so that 1 c c contained about 2 organisms spores or rods.

One $\mathrm{c}$ c of this dilution was inoculated into each of six egg-meat tubes. Dilutions made to contain 1 bacillus or spore per $c \mathrm{c}$ and one-half per $c c$, respectively, were also inoculated into egg-meat tubes and incubated at $37 \mathrm{C}$. for 10 days. At the end of this time the tubes showing growth were tested for toxicity. Four of the tubes diluted to contain approximately two organisms per $\mathrm{c} c$ showed growth; one from each of the other series showed the same kind of growth. These were

5 Jour. Bacteriol., 1919, 4, p. 171. 
found to be nontoxic by mouse inoculation. The action on egg-meat medium was like that of $\mathrm{B}$. sporogenes, being more rapid than the control (the original strain inoculated at the same time). The sugar reactions also were those of $\mathrm{B}$. sporogenes, as is shown in table 2 (see $\mathrm{BI}$ and BII). B. sporogenes was evidently present in numbers far

TABLE 2

Showing Sugar Reactions (Gas) and Toxicity of B. Sporogenes-like Strains Isolated from the Ortginal Stock "Strains" of B. botulinus

\begin{tabular}{|c|c|c|c|c|c|c|c|}
\hline \multirow{2}{*}{$\begin{array}{c}\text { Laboratory Number } \\
\text { of Culture }\end{array}$} & \multicolumn{6}{|c|}{ Percent Gas Formed in } & \multirow{2}{*}{$\begin{array}{l}\text { Toxieity } \\
\text { Tests } \\
\text { on White } \\
\text { Mice }\end{array}$} \\
\hline & $\begin{array}{l}\text { Dex- } \\
\text { trose }\end{array}$ & $\begin{array}{l}\text { Lac- } \\
\text { tose }\end{array}$ & $\begin{array}{l}\text { Sue- } \\
\text { rose }\end{array}$ & $\begin{array}{c}\text { Mal- } \\
\text { tose }\end{array}$ & $\begin{array}{l}\text { Levu- } \\
\text { lose }\end{array}$ & $\begin{array}{c}\text { Galac- } \\
\text { tose }\end{array}$ & \\
\hline 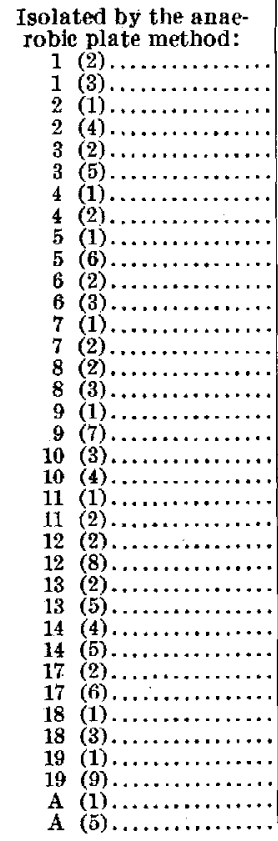 & $\begin{array}{r}90 \\
95 \\
80 \\
100 \\
100 \\
60 \\
50 \\
70 \\
9 \overline{7} \\
70 \\
50 \\
70 \\
70 \\
60 \\
50 \\
60 \\
90 \\
80 \\
75 \\
60 \\
75 \\
60 \\
60 \\
60 \\
60 \\
100 \\
60 \\
50 \\
50 \\
50 \\
80 \\
40 \\
80 \\
50 \\
40 \\
80\end{array}$ & $\begin{array}{c}0 \\
0 \\
0 \\
0 \\
0 \\
0 \\
0 \\
0 \\
0 \\
0 \\
0 \\
\mathrm{~B} \\
0 \\
0 \\
10 \\
+ \\
0 \\
0 \\
0 \\
0 \\
0 \\
0 \\
0 \\
0 \\
0 \\
0 \\
0 \\
0 \\
0 \\
0 \\
0 \\
0 \\
0 \\
0 \\
0 \\
0\end{array}$ & $\begin{array}{l}0 \\
0 \\
0 \\
0 \\
0 \\
0 \\
0 \\
0 \\
0 \\
0 \\
0 \\
0 \\
0 \\
0 \\
+ \\
+ \\
0 \\
0 \\
0 \\
0 \\
0 \\
0 \\
0 \\
0 \\
0 \\
0 \\
0 \\
0 \\
0 \\
0 \\
0 \\
0 \\
0 \\
0 \\
0 \\
0\end{array}$ & $\begin{array}{r}60 \\
60 \\
50 \\
20 \\
90 \\
70 \\
70 \\
80 \\
40 \\
50 \\
60 \\
50 \\
60 \\
40 \\
60 \\
30 \\
30 \\
30 \\
20 \\
30 \\
90 \\
80 \\
40 \\
30 \\
30 \\
40 \\
100 \\
30 \\
60 \\
50 \\
60 \\
60 \\
30 \\
30 \\
60 \\
90\end{array}$ & $\begin{array}{c}10 \\
20 \\
15 \\
+ \\
10 \\
15 \\
60 \\
60 \\
10 \\
10 \\
50 \\
40 \\
30 \\
40 \\
70 \\
60 \\
10 \\
10 \\
10 \\
10 \\
+ \\
10 \\
10 \\
10 \\
10 \\
+ \\
10 \\
10 \\
+ \\
+ \\
10 \\
10 \\
10 \\
10 \\
10 \\
15\end{array}$ & $\begin{array}{c}\mathbf{B} \\
\mathbf{B} \\
0 \\
0 \\
0 \\
0 \\
0 \\
0 \\
0 \\
0 \\
\mathbf{B} \\
\mathbf{B} \\
0 \\
\mathbf{B} \\
\mathbf{B} \\
\mathbf{B} \\
0 \\
0 \\
\mathbf{B} \\
\mathbf{B} \\
0 \\
0 \\
0 \\
\mathbf{B} \\
0 \\
0 \\
0 \\
0 \\
0 \\
0 \\
0 \\
\mathbf{B} \\
0 \\
0 \\
0 \\
\mathbf{B}\end{array}$ & $\begin{array}{l} \pm \\
= \\
= \\
= \\
= \\
= \\
= \\
= \\
= \\
= \\
= \\
= \\
= \\
= \\
= \\
= \\
= \\
= \\
=\end{array}$ \\
\hline 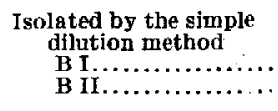 & $\begin{array}{r}100 \\
90\end{array}$ & $\begin{array}{l}0 \\
0\end{array}$ & $\begin{array}{l}0 \\
0\end{array}$ & $\begin{array}{l}90 \\
70\end{array}$ & $\begin{array}{l}15 \\
30\end{array}$ & $\stackrel{0}{\mathbf{B}}$ & $\overline{-}$ \\
\hline $\begin{array}{l}\text { Isolated by the aerobic } \\
\text { method of Sturges, in- } \\
\text { rolving the use of } \\
\text { Staphylococcus aureus: } \\
3+\text { St. .................. } \\
\text { 4+St. ............... }\end{array}$ & $\begin{array}{l}70 \\
60\end{array}$ & $\begin{array}{l}0 \\
0\end{array}$ & $\begin{array}{l}0 \\
0\end{array}$ & $\begin{array}{l}40 \\
50\end{array}$ & $\begin{array}{l}20 \\
20\end{array}$ & $\begin{array}{l}\mathbf{B} \\
0\end{array}$ & $\overline{-}$ \\
\hline $\begin{array}{l}\text { Isolated by the heat- } \\
\text { ing method: } \\
\text { B } 20 . . . \ldots \ldots \ldots \ldots \ldots\end{array}$ & $\mathbf{8 0}$ & $\mathbf{0}$ & 0 & 60 & 15 & $\mathbf{B}$ & - \\
\hline
\end{tabular}


superior to the numbers of $B$. botulinus. This is probably true in many cases, as shown by 2 other strains from which $B$. sporogenes was isolated by the dilution method with the aid of Staphylococcus aureus (see $3+$ St. and $4+$ St. in table 2 ).

Following the other method recommended by Sturges and Rettger, a suspension made up of a mixture of one of the stock strains of $B$. botulinus and of Staphylococcus atreus was plated aerobically, dilutions containing different proportions of these two organisms being plated in series. These were incubated for 2 days at $37 \mathrm{C}$. Fifteen colonies were fished from plates in each series, inoculated into egg-meat medium and incubated at $37 \mathrm{C}$. for 10 days. Only 3 out of 45 inoculated tubes showed anaerobic growth, the others containing Staphylococcus aureus only. One series of plates was made in the same way from another stock strain of $B$. botulinus and Staphylococcus aureus and from this only one isolation was effected which contained an anaerobe, all the other cultures being pure Staphylococcus aureus. All 4 of the anaerobic cultures proved to be nontoxic and, after Staphylococcus aureus had been eliminated by heating at $80 \mathrm{C}$. for 15 minutes, gave all the characteristic reactions of $B$. sporogenes. The nontoxicity of these cultures was confirmed later after a prolonged incubation at room temperature.

These results indicate that B. sporogenes is present in predominating numbers in at least some strains of $B$. botulinus.

B. botulinus has been described by van Frmengem and other European bacteriologists as being a slow spore former. In a special report the British Medical Research Committee in 1919 describes B. botulinus as not forming spores readily, and maintains that these spores when formed are small and do not distend the rod, a character quite different from that ascribed to the organism isolated by American investigators. Spores have been observed in the strains of the series here investigated after an incubation at $37 \mathrm{C}$. of only one or two days. These spores distended the ends of the rods to the same degree at is shown in B. sporogenes cultures grown in the same medium. 'To determine whether or not the spores were those of $B$. botulinus or B. sporogenes the following experiment was performed: four egg-meat tubes and 4 dextrose broth tubes (with a layer of oil on the broth) were inoculated with one of the stock strains of B. botulinus, and all incubated at 37 C. At intervals of 12 hours one inoculated tube of each medium was heated at $80-85 \mathrm{C}$. for 20 minutes. At the end of 48 hours, when all of the tubes had been subjected to heat for the time required to kill vegetative forms, all were inoculated into fresh tubes of egg-meat and incubated at $37 \mathrm{C}$. for 17 days. The results are given in table 3 , sugar reactions included. 
It is apparent from table 3 that the B. botulinus spores did not form until some time between the thirty-sixth and forty-eighth hour after inoculation, but it is also shown that some spores were formed and that the cultures from these surviving spores were nontoxic. The meat medium was digested with the production of putrefactive odor, and the meat was somewhat darkened. The egg-meat medium recommended by Rettger ${ }^{6}$ was used to show proteolytic property. At the end of the first 12 hours not all of the spores of $\mathrm{B}$. botulinus in the meat medium had germinated, hence the toxic culture obtained after heating at $80 \mathrm{C}$. McIntosh and Fildes state that B. sporogenes spores are formed readily and are quite numerous even in the first 21 hours of incubation. This was proved in the foregoing experiment. The nontoxicity of those cultures indicated as nontoxic in the table was confirmed after longer incubation, by feeding to a guinea-pig.

TABLE 3

Resclis OF Expertmext With SPORES

\begin{tabular}{|c|c|c|c|c|c|c|c|c|c|}
\hline \multirow{2}{*}{$\begin{array}{l}\text { Stock } \\
\text { Strain }\end{array}$} & \multirow{2}{*}{$\begin{array}{l}\text { Number } \\
\text { Hours } \\
\text { Ineu- } \\
\text { bated }\end{array}$} & \multirow{2}{*}{ Medium } & \multicolumn{6}{|c|}{ Pereentage Gas In } & \multirow{2}{*}{$\begin{array}{l}\text { Tox- } \\
\text { feity }\end{array}$} \\
\hline & & & $\begin{array}{l}\text { Dex- } \\
\text { trose }\end{array}$ & $\begin{array}{l}\text { Lac- } \\
\text { tose }\end{array}$ & $\begin{array}{l}\text { Suc- } \\
\text { rose }\end{array}$ & $\begin{array}{l}\text { Mal- } \\
\text { tose }\end{array}$ & $\begin{array}{l}\text { Levu- } \\
\text { lose }\end{array}$ & $\begin{array}{c}\text { Galae- } \\
\text { tose }\end{array}$ & \\
\hline 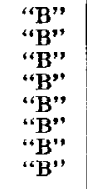 & $\begin{array}{l}12 \\
12 \\
24 \\
24 \\
36 \\
36 \\
48 \\
48\end{array}$ & $\begin{array}{l}\text { Meat } \\
\text { Broth } \\
\text { Meat } \\
\text { Broth } \\
\text { Meat } \\
\text { Broth } \\
\text { Meat } \\
\text { Broth }\end{array}$ & $\begin{array}{l}50 \\
50 \\
60 \\
80 \\
40 \\
40 \\
50 \\
30\end{array}$ & $\begin{array}{l}0 \\
0 \\
0 \\
0 \\
0 \\
0 \\
+ \\
+\end{array}$ & $\begin{array}{l}+ \\
0 \\
0 \\
0 \\
0 \\
0 \\
+ \\
+\end{array}$ & $\begin{array}{l}40 \\
60 \\
60 \\
50 \\
70 \\
60 \\
60 \\
60\end{array}$ & $\begin{array}{l}20 \\
15 \\
15 \\
15 \\
30 \\
10 \\
10 \\
20\end{array}$ & $\begin{array}{c}\text { Bubble } \\
0 \\
0 \\
\text { Bubble } \\
\text { Bubble } \\
\text { Bubble } \\
\text { Bubble } \\
\text { Bubble }\end{array}$ & $\begin{array}{l}+ \\
- \\
- \\
= \\
+ \\
+\end{array}$ \\
\hline
\end{tabular}

The finding of $B$. sporogenes in $B$. botulinus cultures is not a new experience. Burke, in a personal communication, indicates that $\mathrm{B}$. sporogenes is liable to be present in such cultures and describes the appearance in broth of such contaminated cultures. One of the bacteriologic laboratories of this country found the American Museum of Natural History strains of B. botulinus to be, in reality, B. sporogenes. The contaminant in this instance presumably had entirely suppressed and supplanted the toxic $\mathrm{B}$. botulinus. Among the strains first obtained by Shippen ${ }^{7}$ when he began his studies on $B$. botulinus, some were found to be nontoxic. These were strains received by Dickson ${ }^{8}$ from Zinsser and the American Museum of Natural History. Nevin had also noted that these strains had lost their toxic property. It now

b Jour. Biol. Chem., 1906, 2, p. 71.

$\tau$ Arch. Int. Med., 1919, 23, p. 346.

8 Rockefeller Inst. for Med. Research, Monograph 8, Botulism, 1918. 
appears that what actually happened was that the nontoxic B. sporogenes, which was present in the cultures as a contaminant, supplanted the toxic $B$. botulinus. The presence of this rapidly-growing anaerobe in the American strains of $B$. botulinus probably accounts for the varying degrees of toxicity which are accorded them in the literature. This will explain, too, the apparent loss of toxicity of certain American strains.

B. sporogenes is admittedly one of the most widely disseminated of anaerobes. It is common in the classes of materials from which the American strains of $B$. botulinus have been isolated. It is well known, furthermore, that B. sporogenes grows luxuriantly with other organisms. When B. sporogenes and B. botulinus are present in the same material they are so closely associated that it becomes a difficult task to separate them. B. sporogenes, being the less fastidious of the two, is favored by the method of isolation used by American workers. By heating the infected material before diluting in agar, the more resistant form, B. sporogenes, not only survives, but gains the ascendency over B. botulinus. McIntosh recognized this fact and hence did not kill nonspore forms by heating, in his isolation of spore-bearing anaerobes from pus, etc.

The so-called American strains of $B$. botulinus have been obtained from materials which were, beyond all doubt, contaminated with $B$. sporogenes. Such materials were in most cases in an active state of decomposition or spoilage. Dickson ${ }^{8}$ reports the origin of the strains which he isolated up to the beginning of 1917, and refers to the food from which the isolations were made as being spoiled. Burke ${ }^{9}$ isolated strains of $B$. botulinus from sources which are ordinarily heavily seeded with B. sporogenes, for example, moldy hay, manure from a hog which had recovered from botulism, scarred bush beans, spiders from a bush bean plant, etc. B. botulinus in such materials would probably be closely associated with B. sporogenes, from which it would be extremely difficult to separate it. Graham and Brueckner ${ }^{2}$ obtained their strains from moldy hay soiled with chicken excreta, and from silage, materials which in all probability were contaminated with B. sporogenes. Thom, Edmondson and Giltner ${ }^{10}$ isolated B. botulinus from canned asparagus which showed perceptible signs of spoilage. Armstrong ${ }^{11}$ obtained his organism from olives which had caused a small epidemic of botulism

- Jour. Bact., 1919, 4, p. 541.

10 Jour. Am. Med. Assn., 1919, 73, p. 907.

It Public Health Reports, 1919, 34, p. 2877. 
and which "smelled like limberger cheese." Edmondson, DeBord and Thom, ${ }^{12}$ reporting results of bacteriologic tests of 510 samples of canned olives, found B. botulinus in 7 cans, all of which showed signs of spoilage. Enterson and Collins, ${ }^{13}$ on the other hand, iso'ated their strain from canned olives which gave an odor resembling that of rancid butter.

Most European strains have been isolated from sources relatively free from this contaminant. Putrefactive decomposition is not associated with the occurrence of the organism in the food from which they were obtained. Van Ermengem ${ }^{1}$ procured the original strain of $B$. botulinus from an apparently normal ham which showed no signs of decomposition or spoilage. The organism isolated did not give repulsive odors in any medium used, even in meat, peptone bouillon, etc. Only a sour odor is mentioned, the absence of any foul odors being emphasized. Römer ${ }^{14}$ obtained his strain of $\mathrm{B}$. botulinus from a portion of a ham which had been exposed to the air and which had lost its natural color and consistency, had turned greenish, and which had developed a butyric acid, but not putrefactive odor. No mention was made of putrefactive decomposition. Madsen ${ }^{15}$ isolated $\mathrm{B}$. botulinus from fish which had an intense butyric odor and which had caused botulism. Van Ermengem in 1906 again obtained a strain similar to the one previously isolated, from another ham which had a disagreeable, more or less rancid, odor, but he does not mention any signs of putrefactive decomposition. In one place on the ham there was a brownish spot which was of a slimy consistency; from this area the isolation was made. Landmann, ${ }^{16}$ in reporting his work on the Darmstadt outbreak, did not mention any spoilage of the beans which had caused the outbreak. Schumacher ${ }^{17}$ described the ham which was responsible for 6 cases of botulism as smelling rancid. Ornstein ${ }^{18}$ reported the deaths of 2 persons who had eaten ham which had merely a butyric odor. These descriptions of the materials from which $\mathrm{B}$. botulinus was isolated by European bacteriologists are in more or less contrast to those recorded by American investigators. The absence of foul odors accounts, in part, for the apparent ease with which the European strains were

\footnotetext{
12 Bacteriol. Abstracts, 1919, 4, p. 10.

12 Jour. Lab. \& Clin. Med., 1920, 5, p. 559.

14 Centralbl. f. Bakteriol, 1900, 27, p. 857.

15 Cited by Van Ermengem, Kolle and Wassermann, Handbuch, 1912, 4, p. 909.

16 Hyg. Rundschau, 1904, 14, p. 449.

17 Münch. med. Wchnschr., 1913, 60, p. 124.

is $Z$ tschr. f. Chemotherapie, 1912,1, p. 458.
} 
obtained pure, for B. sporogenes was probably not present in large numbers, if at all.

No mention is made by the European investigators of proteolytic properties of their strains other than gelatin liquefaction. On the other hand, the American strains have been described as being decidedly proteolytic, digesting meat with the production of the characteristic odors of putrefaction and peptonizing milk. Gelatin is liquefied, of course. The van Ermengem strain does not grow well in milk and does not coagulate or peptonize it (van Ermengem ${ }^{15}$ ). McIntosh and Fildes state that it does not grow well in meat either. This is in marked contrast to the reported cultural characters of the American strains. Von Hibler ${ }^{19}$ however, working with a strain of $\mathrm{B}$. botulinus obtained from the Kral (Vienna) collection, describes it as being decidedly proteolytic, digesting coagulated serum and clotting and peptonizing milk. McIntosh and Fildes ${ }^{3}$ found B. sporogenes in the strain of B. botulinus obtained by them from Kral, the source of von Hibler's strains. Van Ermengem claims von Hibler was working with cultures which were of very low toxicity. The presence of $B$. sporogenes in the culture could easily account for the low toxicity if it were present in predominating numbers. Dickson compared his isolations with the strains of $\mathrm{B}$. botulinus described by von Hibler and noted the same proteolytic activity in milk as von Hibler did.

The American strains obtained by the writer from various sources are indistinguishable from each other culturally, including the Dickson strains. They all digest meat with the evolution of putrefactive gases. They peptonize milk in the same manner as pure cultures of B. sporogenes, but in some cases not quite so rapidly. In meat the action of B. sporogenes is more rapid than that of the B. botulinus stock strains, but the appearance of the medium is quite similar. At first the odor from the latter is not so strongly putrefactive as later, slightly resembling that of butyric acid during the first day's incubation.

It cannot be said that any of the toxic "strains" are pure B. botulinus. They, like the original stock cultures, show every indication of being mixed cultures of $\mathrm{B}$. botulinus and $\mathrm{B}$, sporogenes. The surface colonies which answered the description of typical colonies of B. botulinus contained, besides the botulism organism, at least a small number of $B$. sporogenes. On the other hand, some of the typical B. sporogenes colonies were proved to enclose B. botulinus bacilli or spores.

19 Untersuchungen über die anaeroben, 1908. 
Inability of the author thus far to isolate B. botulinus may be explained readily as follows: This organism is slow to develop from single isolated cells, hence fails to appear in pure colony form. B. sporogenes is a hardy anaerobe, and may be isolated without difficulty from almost any source. On the agar plates this organism favors the former. Other examples of organisms which are isolated only with the greatest difficulty are $B$. putrificus, and perhaps to a somewhat lesser extent, B. tetani. It can be no exaggeration to say that very few cultures of $B$. putrificus have as yet been obtained, and that among the stock cultures of $B$. tetani in the different laboratories few are pure cultures.

The sources from which American strains of B. botulinus have been obtained have been such that close association of this organism with B. sporogenes must be taken as a matter of fact. Therefore, the problem of isolation of the botulism bacillus is naturally a difficult one. Attempts now being made by the author to obtain pure cultures which answer the description, or at least proximate, that given by van Ermengem and other European investigators, include long and repeated enrichment cultivation in particularly favorable evironment, that is, special carbohydrate mediums, etc.

The finding of $\mathrm{B}$. sporogenes as a contaminant of the American strains of $B$. botulinus is of considerable importance. The results explain clearly the reasons for the sharp differences noted in the descriptions of the organism given by the European and American investigators. The use of impure cultures in the making of antiserum is unsatisfactory and may account for the absence of uniformity of results in the treatment of botulism victims. The use of antiserums in the prophylaxis of botulism has given good results experimentally in some instances, but it has not as yet been pronounced a success in actual practice. The toxicity of the strains of $\mathrm{B}$. botulinus which are contaminated with B. sporogenes will vary with the age of the culture and with the proportion in which the contaminant is present.

The differences noted between the so-called "strains" of the present collection and the descriptions of B. botulinus given by van Ermengem and other European bacteriologists are so marked as to exclude them from being members of the same species. The marked proteolytic property alone of the American "strains" is sufficient to separate them entirely from the European strains. These differences can readily be accounted for by the presence of a contaminant like B. sporogenes in the American "strains." 


\section{SUMMARY}

Nontoxic strains were isolated from 18 out of 19 so-called "strains" of $\mathrm{B}$. botulinus examined. These nontoxic isolations were proved to be $B$. sporogenes.

Isolations of B. sporogenes were made from stock "strains" of B. botulinus by 4 different methods, that is, by the use of anaerobic plates, simple dilution, aerobic plates with Staphylococcus aureus, and by heating in order to kill regetative forms after the spores of $B$. sporogenes had been formed.

The "strains" of B. botulinus examined resemble morphologically and in their action on meat mediums and milk pure cultures of $\mathrm{B}$. sporogenes, except that the action of $\mathrm{B}$. sporogenes is more rapid, and in some cases carried nearer to completion. 